\title{
The incidence of arthropathy adverse events in efalizumab-treated patients is low and similar to placebo and does not increase with long-term treatment: pooled analysis of data from Phase III clinical trials of efalizumab
}

\author{
Carlo Pincelli • Eric Henninger • \\ Florence Casset-Semanaz
}

Received: 11 May 2006 / Revised: 8 August 2006 / Accepted: 17 August 2006 / Published online: 21 September 2006

(C) Springer-Verlag 2006

\begin{abstract}
A large-scale, pooled analysis of safety data from five Phase III clinical trials (including open-label extensions of two of these studies) and two Phase III open-label clinical trials of efalizumab was conducted to explore whether arthropathy adverse events (AEs) were associated with efalizumab treatment in patients with moderate-to-severe chronic plaque psoriasis. Data from patients who received subcutaneous injections of efalizumab or placebo were stratified for analysis into phases according to the nature and duration of treatment. These included: the 'first treatment' phase (0-12week data from patients who received either efalizumab, $1 \mathrm{mg} / \mathrm{kg}$ once weekly, or placebo in the five placebo-controlled studies); the 'extended treatment' phase (13-24-week data from seven trials for all efalizumab-treated patients); and the 'long-term treatment' phase (data from efalizumab-treated patients who received treatment for up to 36 months in two long-term trials). Descriptive statistics were performed and the incidence of arthropathy AEs per patient-year was calculated using $95 \%$ confidence intervals (CIs). During the first treatment phase, a similar proportion of patients had an arthropathy AE in the efalizumab group $(3.3 \% ; 58 / 1740$ patients) compared with the
\end{abstract}

C. Pincelli

Department of Medicine, Institute of Dermatology, University of Modena and Reggio Emilia, Modena, Italy e-mail: carlo@unimo.it

E. Henninger $(\varangle) \cdot$ F. Casset-Semanaz Serono International S.A., 15bis Chemin des Mines, 1202 Geneva, Switzerland

e-mail: eric.henninger@serono.com placebo group (3.5\%; 34/979 patients); the incidence of arthropathy AEs per patient-year was 0.15 in the efalizumab group (95\% CI $0.11-0.19)$ and 0.16 in the placebo group (95\% CI 0.11-0.22). Analysis of first treatment phase data from one study $(n=793)$ showed that the incidence of psoriatic arthropathy per patientyear was lower in efalizumab-treated patients $(0.10$; 95\% CI $0.05-0.18)$ than in those given placebo $(0.17$; 95\% CI 0.08-0.30). During the extended treatment phase, the incidence of arthropathy remained low (0.17; $95 \%$ CI $0.14-0.22)$. Data from two long-term studies showed that there was no increase in the incidence of arthropathy AEs over time in patients treated with efalizumab for up to 36 months. Patients who had an arthropathy AE during treatment with efalizumab appeared to be more likely to have a history of arthropathy prior to treatment. Efalizumab does not appear to increase the risk of arthropathy AEs compared with placebo.

Keywords Arthropathy · Arthritis · Efalizumab · Psoriasis · Psoriatic arthritis

\section{Introduction}

Psoriasis is a chronic, immune-mediated, inflammatory skin disorder that is currently incurable. Consequently, the majority of people with psoriasis require long-term treatment to maintain disease control. Traditional immunosuppressive systemic treatments, such as acitretin, methotrexate, cyclosporine, hydroxyurea, and thioguanine, may be effective in controlling psoriasis in some patients but significant toxicity and the need to closely monitor patients limit the viability of these 
treatments for long-term, continuous use [23]. Recently developed systemic therapies that selectively target specific pathways in the inflammatory cascade of psoriasis generally have a much improved safety profile compared with traditional therapies [26].

Efalizumab (anti-CD11a; Raptiva ${ }^{\circledR}$ ) is a recombinant humanized monoclonal $\mathrm{IgG}_{1}$ antibody that has been approved for the treatment of moderate-tosevere chronic plaque psoriasis. It interferes with the pathogenesis of psoriasis via multiple mechanisms, including inhibition of T-lymphocyte trafficking and Tlymphocyte activation and reactivation $[1,10,11,21$, 25]. The safety and efficacy profile of efalizumab has been established in numerous clinical trials, in which more than 3,500 patients were enrolled and treatment was assessed for up to 3 years [4-6, 12-17, 22].

Although psoriasis can be associated with the comorbidity of psoriatic arthritis, a minority of patients with psoriasis $(7-30 \%)$ will develop this joint disease [27]. Nevertheless, psoriatic arthritis constitutes a major consideration in patients who are receiving longterm treatment for their psoriasis. A Nordic study of more than 5,000 patients with psoriasis showed that patients with arthritis exhibited greater impairment of psoriasis-related quality of life (QoL), longer disease duration, and greater self-reported disease severity, compared with patients who had psoriasis but no comorbid arthritis [27].

A low incidence of arthropathy adverse events (AEs; any form of joint disease) associated with efalizumab treatment has been reported in both clinical studies and routine clinical practice $[8,12]$. However, anecdotal reports of arthropathy in routine clinical practice have expressed concern that efalizumab may be associated with exacerbation of arthropathy [8]. To address this concern, we conducted a large-scale pooled analysis of safety data from five Phase III clinical trials (including open-label extensions of two of these studies) and two Phase III openlabel clinical trials of efalizumab to explore whether arthropathy AEs were associated with efalizumab treatment in patients with psoriasis.

\section{Methods}

The primary objective of this pooled safety analysis was to assess the incidence of arthropathy AEs in patients who had received either efalizumab or placebo. Safety data were pooled from five randomized, double-blind, placebo-controlled clinical trials (including data from two open-label extension studies of two of these trials) and two open-label clinical trials of efalizumab [4-6, 12-17, 22]. Patients included in these Phase III studies were aged $\geq 18$ years and had moderate-to-severe chronic plaque psoriasis, a psoriasis area and severity index (PASI) score of $\geq 12$ at screening, and plaque psoriasis covering $\geq 10 \%$ of body surface area. All patients were candidates for either systemic anti-psoriatic therapy or had received systemic antipsoriatic therapy. Patients included in these trials received subcutaneous injections with efalizumab, 1$4 \mathrm{mg} / \mathrm{kg}$ once weekly or $2 \mathrm{mg} / \mathrm{kg}$ once-every-other week, or placebo. Details of individual study methodologies are described in other publications [4-6, 12-17, 22].

Arthropathy AEs were defined according to the Coding Symbols for Thesaurus of Adverse Reaction Terms (COSTART) [3] preferred terms 'arthritis' and 'arthrosis', or the Medical Dictionary for Regulatory Activities (MedDRA, http://www.meddramsso.com/NewWeb2003/ index.htm) preferred terms 'arthritis not otherwise specified (NOS)', 'psoriatic arthropathy', 'arthropathy NOS', 'monoarthritis', 'polyarthritis', and 'osteoarthritis NOS'.

\section{Treatment groups analyzed}

Due to the variety of study designs, five analyses were considered: 'first-treatment phase', 'first exposure phase', 'extended treatment phase', 're-treatment phase', and 'long-term treatment' (see Table 1).

It is worth noting that most of the studies included in this pooled analysis were designed and conducted before efalizumab had received regulatory approval and before it was known that doses of more than $1 \mathrm{mg} / \mathrm{kg}$ once weekly (the approved dose) did not confer additional treatment benefit (EMEA, Raptiva Summary of Product Characteristics; FDA US, FDA Prescribing Information for Raptiva). For this reason, only the efalizumab $1 \mathrm{mg} /$ $\mathrm{kg}$ once-weekly dose data are reported for the 'first treatment phase' of the analysis. Due to the wide variety of study designs included in the pooled analysis, data for patients receiving any dose of efalizumab are combined for all other treatment phases analyzed.

The 'first treatment phase' analysis included 0-12week data from patients in the five placebo-controlled studies who received either efalizumab $1 \mathrm{mg} / \mathrm{kg}$ once weekly or placebo. This analysis allows a comparison between the efalizumab and placebo treatment groups.

The 'first exposure phase' included 12-week data from all studies in patients who had their first exposure to any dose of efalizumab and, thus, did not include placebo data. This analysis was conducted to include the maximum number of patients who received efalizumab for their first 12 weeks of treatment (i.e., it included those patients who first received efalizumab 


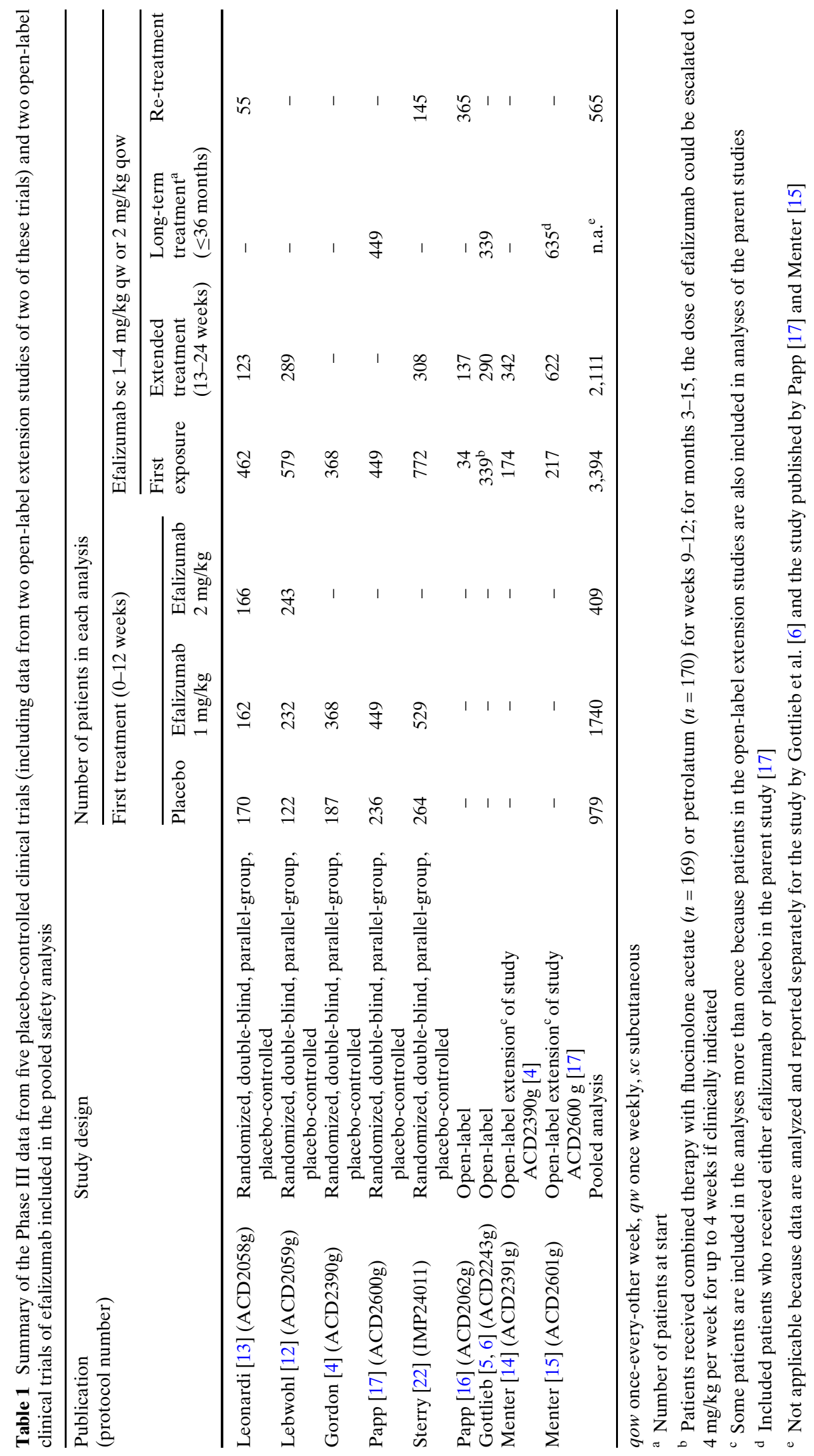


treatment after crossing over from a placebo group, as well as the patients who first received efalizumab during weeks $0-12$ ).

The 'extended treatment phase' analysis included 13-24-week data in patients given any dose of efalizumab who had already received efalizumab during the first treatment phase.

The 'long-term treatment phase' analysis included all patients who received continuous long-term treatment (up to 36 months) with any dose of efalizumab. Data were analyzed in 12-week segments to assess change in the incidence of arthropathy AEs over time. This analysis included data from two long-term studies $[6,15,17]$, which were analyzed separately due to differences in study design.

The 're-treatment phase' analysis included all patients who re-started treatment with efalizumab following a treatment-free observation period.

\section{Statistical analyses}

Descriptive statistics were used to explore the association between efalizumab and the occurrence of arthropathy AEs. Results are expressed as point-estimates of the incidence rates (ratio of the number of patients with an arthropathy AE to the total number of patient-years at risk of an arthropathy AE) with their 95\% confidence intervals (CIs). Descriptive comparisons are provided; no formal statistical tests were performed.

Analyses were also conducted to explore the relationship between onset of arthropathy AEs during efalizumab treatment and a previous history of arthropathy (reported as a narrative by patients at the baseline visit) and the incidence of arthropathy AEs and clinical response to efalizumab treatment [measured at 12 weeks using the Physician Global Assessment (PGA) and PASI scales]. Differences in patient and psoriasis characteristics at baseline were also compared between patients who had arthropathy AEs and those who did not. An additional analysis of data from patients included in the first treatment phase of the study by Sterry et al. [22] (Table 1) was conducted to assess the incidence of psoriatic arthropathy in these patients. This was the only study to define arthropathy AEs according to MedDRA; other studies used the COSTART, which did not include 'psoriatic arthropathy' specifically as a preferred term.

Baseline demographics and psoriasis characteristics and the proportion of patients with a previous history of arthropathy (as reported by patients at the baseline visit) were tabulated by presence/absence of an arthropathy event.

\section{Results}

The number of patients included in each of the pooled safety analyses from each of the seven trials and two open-label extensions is summarized in Table 1. Up to 3,394 patients received at least one dose of efalizumab. A total of 2,719 patients were included in the first treatment phase analysis, of whom the majority $(64 \% ; 1,740$ patients) received efalizumab $1 \mathrm{mg} / \mathrm{kg}$ per week; 979 patients $(36 \%)$ received placebo. Efalizumab $2 \mathrm{mg} / \mathrm{kg}$ per week regimen was given to 409 patients $(15 \%)$ in two of the five studies [12, 13]; consequently, these patients were not included in the first treatment analysis. Patient demographics and baseline psoriasis characteristics were similar between treatment groups in the first treatment phase (Table 2).

First treatment phase (weeks 0-12)

During the first 12 weeks of treatment a similar proportion of patients had an arthropathy $\mathrm{AE}$ in the

Table 2 Baseline demographic and disease characteristics for patients in the placebo-controlled first treatment phase

\begin{tabular}{|c|c|c|c|}
\hline Characteristics & $\begin{array}{l}\text { Placebo } \\
(n=979)\end{array}$ & $\begin{array}{l}\text { Efalizumab } 1 \mathrm{mg} / \mathrm{kg} \text { per } \\
\text { week }(n=1,740)\end{array}$ & $\begin{array}{l}\text { Efalizumab } 2 \mathrm{mg} / \mathrm{kg} \\
\text { per week }(n=409)\end{array}$ \\
\hline Mean age (years), mean (SD) & $45(12)$ & $45(12)$ & $45(13)$ \\
\hline Weight (kg), mean (SD) & $90.0(20.0)$ & $89.4(19.6)$ & $93.6(20.5)$ \\
\hline Mean $\mathrm{BMI}^{\mathrm{a}}\left(\mathrm{kg} / \mathrm{m}^{2}\right)$ & $30.4(6.4)$ & $30.2(6.3)$ & $31.4(6.6)$ \\
\hline \multicolumn{4}{|l|}{ Race, $n(\%)$} \\
\hline Caucasian & $891(91)$ & $1,569(90)$ & $356(87)$ \\
\hline Other & $88(9)$ & $171(10)$ & $53(13)$ \\
\hline $\begin{array}{l}\text { Duration of psoriasis, mean } \\
\text { number of years (SD) }\end{array}$ & $19.2(11.4)$ & $19.1(11.4)$ & $17.6(11.7)$ \\
\hline History of arthritis, $n(\%)$ & $286(29.2)$ & $529(30.4)$ & $141(34.5)$ \\
\hline
\end{tabular}

$B M I$ body mass index

${ }^{a}$ Due to missing height data, BMI was calculated for 971 patients in the placebo group, 1,719 patients in the efalizumab $1 \mathrm{mg} / \mathrm{kg}$ per week group and 404 patients in the efalizumab $2 \mathrm{mg} / \mathrm{kg}$ per week group 
efalizumab $1 \mathrm{mg} / \mathrm{kg}$ group (3.3\%) and the placebo group (3.5\%; Fig. 1a). Correspondingly, the incidence of arthropathy AEs per patient-year was 0.15 in the efalizumab $1 \mathrm{mg} / \mathrm{kg}$ group (95\% CI $0.11-0.19$ ) and 0.16 in the placebo group (95\% CI 0.11-0.22; Fig. 1b). The majority of the arthropathy AEs was mild-to-moderate in intensity in both the efalizumab (41/58 events; $71 \%$; $95 \%$ CI $57-82 \%)$ and placebo groups (31/34 events; 91\%; 95\% CI 76-98\%).

The additional analysis of data from the study by Sterry et al. [22] demonstrated that the incidence of psoriatic arthropathy per patient-year was lower in the group treated with efalizumab $1 \mathrm{mg} / \mathrm{kg}$ per week $(0.10$; $95 \%$ CI $0.05-0.18)$ than in the placebo group ( 0.17 ; 95\% CI 0.08-0.30); the proportion of patients with psoriatic arthropathy was $2.3 \%$ (12/529 patients) in the efalizumab group and $3.8 \%$ (10/264 patients) in the placebo group.

First exposure phase

In total, 3,394 efalizumab-treated patients were included in this analysis. A small proportion of patients had an arthropathy AE (3.6\%; Fig. 1a) and the inci-

(a)

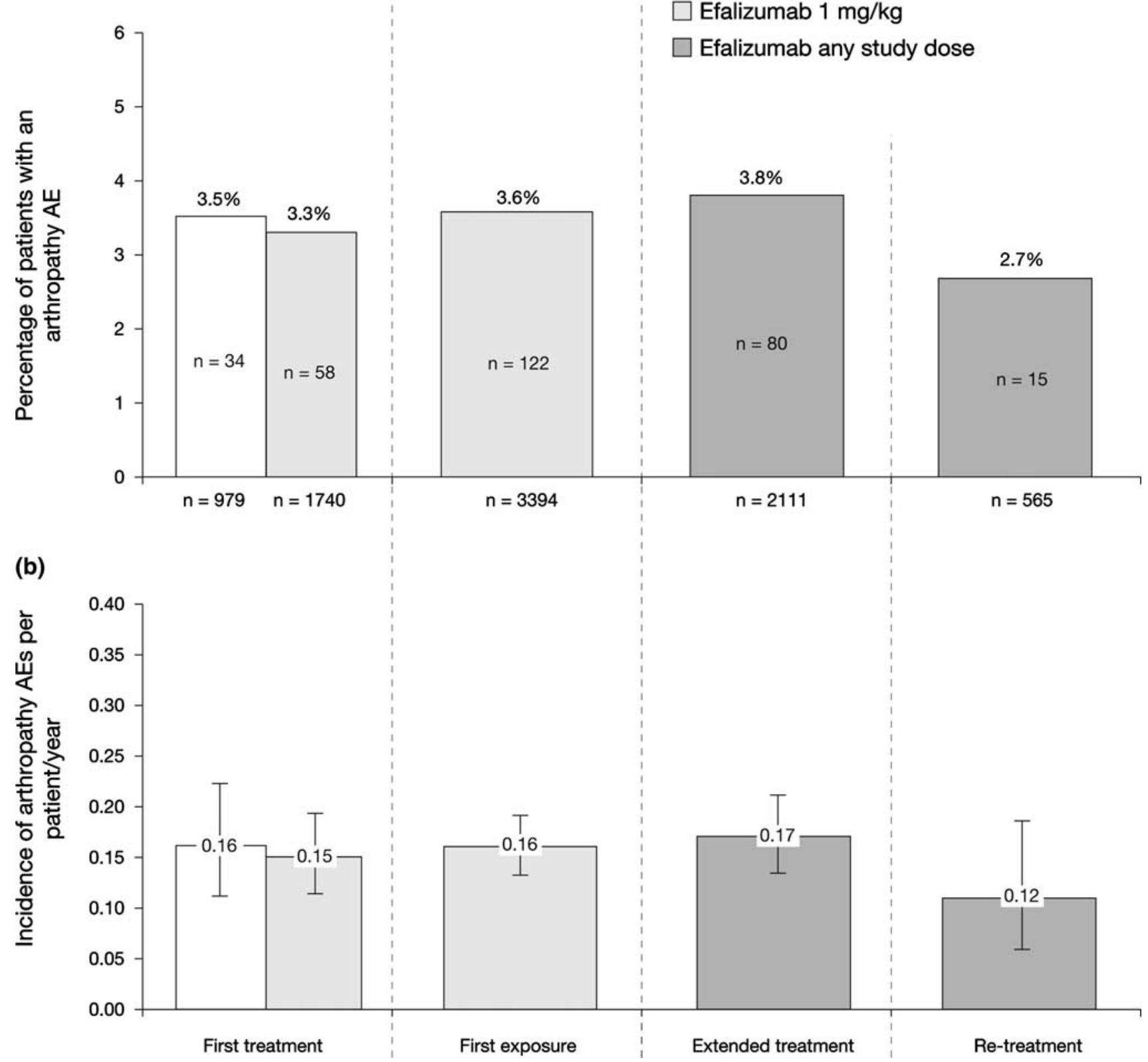

Fig. 1 a Proportion of patients who had arthropathy adverse events (AEs) during each phase of the safety analysis and $\mathbf{b}$ incidence of arthropathy AEs per patient-year for each phase 
dence of arthropathy AEs per patient-year was also low (0.16; 95\% CI 0.14-0.19; Fig. 1b).

The incidence of arthropathy AEs in this group of patients was similar to that in the placebo group in the first treatment phase, as indicated by the overlap in CIs.

\section{Extended treatment phase (weeks 13-24)}

In total, 2,111 patients were included in the extended treatment phase analysis. During this phase, a low proportion of patients had an arthropathy AE (3.8\%; Fig. 1a) and the incidence of arthropathy AEs per patient-year was also low $(0.17 ; 95 \%$ CI $0.14-0.22$; Fig. 1b). Overlap in the CIs indicates that the incidence of arthropathy AEs in this group of patients was also similar to that in the placebo group in the first treatment phase.

Long-term treatment phase

The results of two long-term studies were analyzed separately to assess the incidence of arthropathy AEs in patients treated with efalizumab. In both of these studies (Fig. 2), there was no overall increase in the incidence of arthropathy AEs over time. Furthermore, the incidence of arthropathy remained similar to that of the placebo group in the first treatment phase and stable between 12 -week periods.

In total, 339 patients were included in the analysis of the study by Gottlieb et al. [6]. These patients received continuous treatment with efalizumab $2 \mathrm{mg} / \mathrm{kg}$ once weekly for weeks 1-12 (fluocinolone acetate or petrolatum was co-administered during weeks 9-12), followed by continuous maintenance treatment with efalizumab $1 \mathrm{mg} / \mathrm{kg}$ once weekly for up to 36 months in patients who had $\mathrm{a} \geq 50 \%$ improvement in PASI score. For months 3-15, the dose of efalizumab could be escalated to $4 \mathrm{mg} / \mathrm{kg}$ per week for up to 4 weeks if clinically indicated, then maintained at $2 \mathrm{mg} / \mathrm{kg}$ per week. During the entire study period, there was little variation in the incidence of arthropathy AEs (range 0.06-0.19; Fig. 2a). Reasons for discontinuation were diverse and were representative of the overall population; refer to Gottlieb et al. [6, 7] for details of discontinuations.

For the other long-term study, the analysis included 3-month data from 449 efalizumab-treated patients in the placebo-controlled first treatment phase of the study [17] and data from 635 patients who entered the open-label extension phase and received efalizumab treatment [15]; 218 of the 635 patients included in the open-label extension had switched from placebo to efalizumab after completing the first treatment phase.
Patients who entered the open-label extension phase continued to receive, or initiated treatment with, efalizumab $1 \mathrm{mg} / \mathrm{kg}$ once weekly for up to 15 months continuously. As in the long-term study by Gottlieb et al. [6], there was little variation in the incidence of arthropathy AEs during the entire study period (range $0.06-0.12$; Fig. 2b).

\section{Re-treatment phase}

In total, 565 efalizumab-treated patients were included in the re-treatment phase of the analysis. In this phase, a lower proportion of patients had an arthropathy AE (2.7\%; Fig. 1a) compared with the first treatment phase, and the incidence of arthropathy AEs per patient-year was also lower $(0.12$; $95 \%$ CI $0.07-0.19$; Fig. 1b). The incidence of arthropathy AEs in this group of patients was lower than in the placebo group in the first treatment phase.

Baseline characteristics and previous history of arthropathy

There were no differences in baseline demographics or disease characteristics between the patients who had arthropathy AEs and those who did not. Patients who experienced an arthropathy AE during treatment with efalizumab appeared to be more likely to have a history of arthropathy prior to treatment. Of the patients who never developed an arthropathy AE during efalizumab treatment, $27 \%$ reported a previous history of arthropathy compared with 59\% in patients who did have an arthropathy AE.

During the first treatment phase, $88 \%(n=34)$ and $76 \%(n=79)$ of patients who developed an arthropathy AE had a history of arthropathy prior to receiving placebo or efalizumab $1 \mathrm{mg} / \mathrm{kg}$ once weekly, respectively.

Arthropathy AEs and clinical response to efalizumab

Arthropathy AEs appeared to be less likely to occur in patients who had a good clinical response to treatment ( $\geq 75 \%$ improvement in PASI score; $2.3 \%$ of patients had events) than in patients who had a partial response (50-74\% improvement in PASI score; $3.5 \%$ of patients had events; Fig. 3$)$ and non-responders ( $<50 \%$ improvement in PASI score; $4.5 \%$ of patients had events). The corresponding incidences of arthropathy AEs per patient-year were 0.10 in patients with a good clinical response (95\% CI 0.05-0.18), 0.17 in patients with a partial clinical response (95\% CI $0.11-0.25)$, and 0.21 in patients who did not respond (95\% CI 0.15-0.28). 

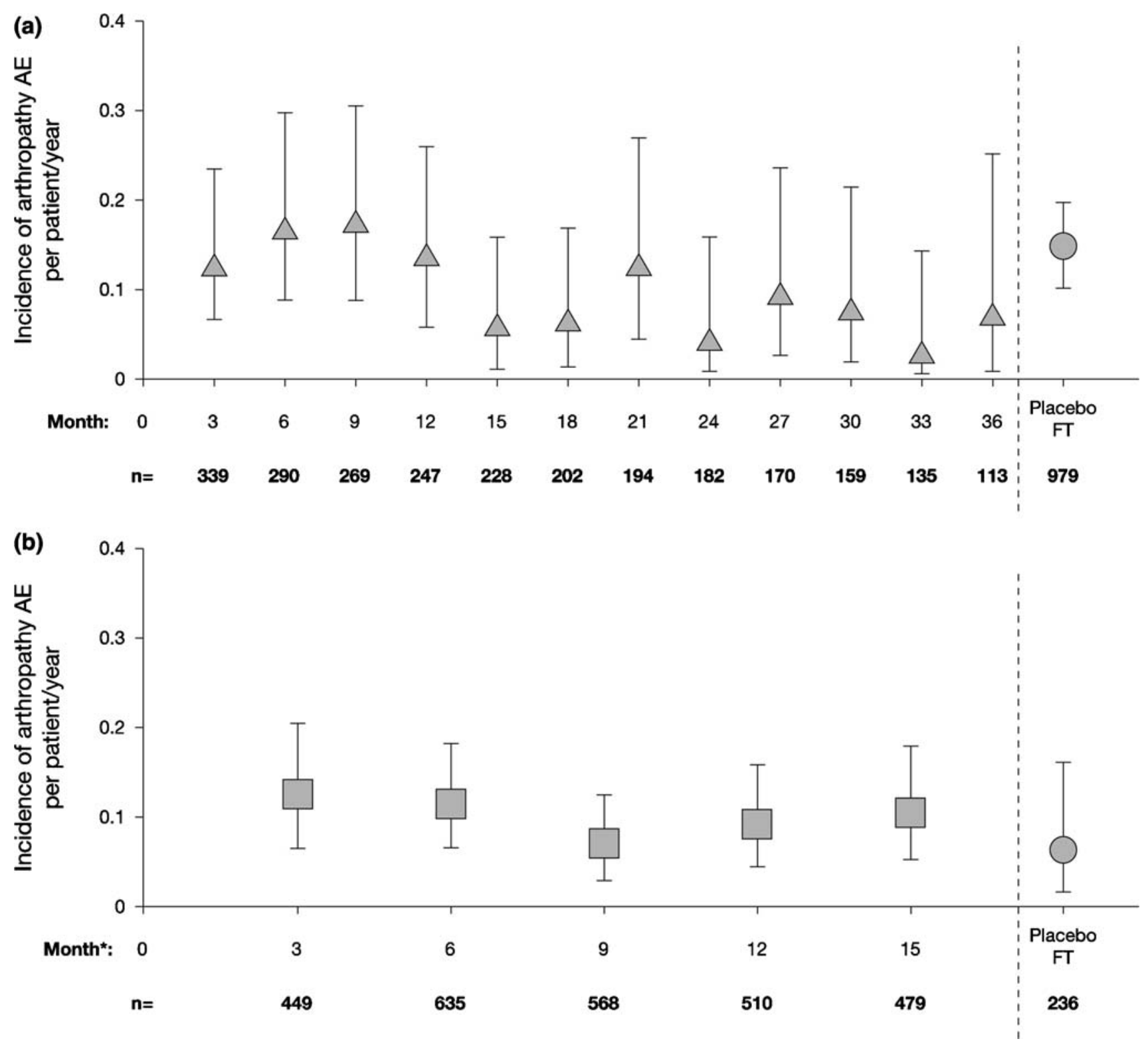

Fig. 2 Incidence of arthropathy AEs in long-term studies of patients treated with efalizumab a for up to 36 months and compared indirectly with pooled placebo data from the first treatment (FT) phase [5,6] and $\mathbf{b}$ for up to 15 months and compared with the study's placebo group during month $0-12$ [15, 17]. *Following the first 3-month double-blind, placebo-controlled phase of this study, patients in the placebo group who continued were switched to open-label treatment with efalizumab. Consequently, the month $6,9,12$ and 15 results included patients who had received placebo during the initial 3 months of the study
When assessed using the PGA scale, arthropathy AEs also appeared to be less likely to occur in patients who had better clinical responses to treatment with efalizumab (Fig. 3). During the extended treatment phase, the incidence of arthropathy AEs per patientyear was 0.17 in patients with responses categorized as 'cleared', 'excellent' or 'good' on the PGA scale (95\% CI $0.10-0.25$ ) and 0.25 in patients with responses categorized as 'fair', 'slight', 'unchanged' or 'worse' on the PGA scale (95\% CI 0.17-0.35).

\section{Discussion}

The placebo-controlled results of this large-scale pooled analysis of arthropathy data from seven clinical trials show that efalizumab does not appear to increase the risk of developing arthropathy AEs compared with placebo during the first 12 weeks of treatment. In addition, for patients treated with efalizumab, the incidence of arthropathy AEs did not appear to increase over time. The proportion of patients who had an arthropathy AE 

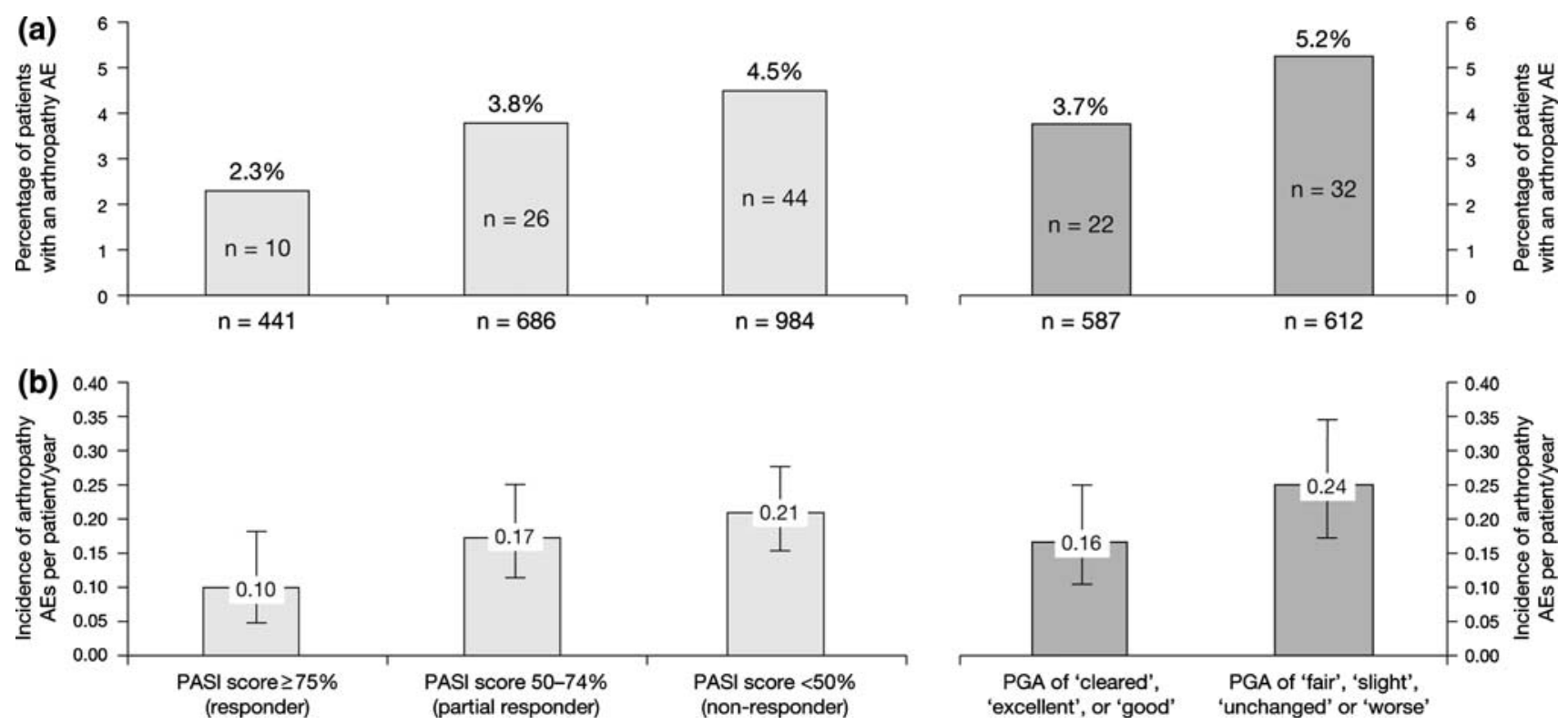

Fig. 3 a Proportion of patients with an arthropathy AE by response category on the psoriasis area and severity index (PASI) and physician global assessment (PGA) scales and $\mathbf{b}$ incidence of

within any 12 -week treatment period was low $(<4.1 \%)$ through all treatment phases (first treatment, first exposure, extended treatment, re-treatment, long-term treatment).

Joint disease has also been reported as a side-effect of other approved biological treatments for psoriasis, namely infliximab (EMEA public statement on infliximab, http://www.emea.eu.int/pdfs/human/press/pus/4 44500en.pdf) $[2,18,19]$, alefacept (Biogen safety presentation on Alefacept to the FDA, http://www.fda.gov/ ohrms/dockets/ac/02/slides/3865S1_04_Biogen-Safety/ sld007.htm) [20, 24], and etanercept (EMEA Scientific discussion for the approval of Enbrel, http://www. emea.eu.int/humandocs/PDFs/EPAR/Enbrel/014600e n6.pdf). Indeed, placebo-controlled studies of infliximab and alefacept indicate that in patients with moderate-to-severe psoriasis the incidence of arthralgia (joint pain) is 7 and 5\%, respectively (Biogen safety presentation on Alefacept to the FDA, http://www. fda.gov/ohrms/dockets/ac/02/slides/3865S1_04_BiogenSafety/sld007.htm) [18, 24]. Psoriatic arthritis has been reported as serious treatment-related AE in three placebo-controlled studies of etanercept in the treatment of chronic plaque psoriasis (incidence data have not been published) (EMEA Scientific discussion for the approval of Enbrel, http://www.emea.eu.int/humandocs/PDFs/EPAR/Enbrel/014600en6.pdf). The incidence of arthropathy AEs in the current analysis of efalizumab appears to be similar to that for arthralgia in studies of infliximab and alefacept. Moreover, the term 'arthropathy', used in the current study encompasses a arthropathy AEs per patient-year by response category on the PASI and PGA scales

variety of joint diseases, not just a single joint condition such as arthralgia or psoriatic arthritis, and therefore has greater potential to include more patients. However, this between-study comparison is indirect and thus should be treated with caution. Moreover, no arthropathy event (defined by any of the MedDRA or COSTART preferred terms) was excluded from the analysis. Also, data from first treatment phase of the study by Sterry et al. [22] indicate that the proportion of patients with psoriatic arthropathy specifically was low $(2.3 \%)$ in patients treated with efalizumab $1 \mathrm{mg} / \mathrm{kg}$ per week-in fact, lower than in the placebo group $(3.8 \%)$. It should be noted, however, that psoriatic arthropathy events were not confirmed by a rheumatologist-this is a potential limitation of the study. However, the umbrella term 'arthropathy' was designed to capture all joint diseases, including 'psoriatic arthropathy'. Also, the incidence of psoriatic arthropathy in the study by Sterry et al. was in line with the incidence of 'arthropathy' in the overall pooled analysis.

To put the results of this pooled analysis, which by its very nature included select patient populations (determined by the inclusion/exclusion criteria and study designs), in the context of routine clinical practice, post-marketing surveillance data were assessed. During post-marketing surveillance of efalizumab, which accounts for approximately 17,500 patient-years to date, serious arthropathies requiring hospitalization were reported with a frequency of about 4.8 per 1,000 patient-years in patients receiving efalizumab. It 
should be noted, however, that underreporting of AEs in routine clinical practice setting may lead to an underestimate of the true incidence of arthropathy.

For both the 12-week first treatment and first exposure phases of the current analyses, the proportions of patients reporting an arthropathy AE appeared to be lower in the efalizumab groups than in the placebo group in the first treatment phase. Correspondingly, the incidences of AEs per patient-year in these treatment phases were also lower in the efalizumab groups than that observed in the placebo group in the first treatment phase. However, the proportion of AEs that were moderate or severe was greater in the efalizumab groups than in the placebo groups; too few patients had events to draw any meaningful conclusions.

During the extension phase (weeks 13-24), the incidence of arthropathy AEs in efalizumab-treated patients remained similar to the placebo group in the first treatment phase. Previous history of arthropathy and poor clinical response may potentially indicate a risk for occurrence of new arthropathy AEs during treatment. Indeed, arthropathy AEs were most frequent in patients who did not respond to therapy with efalizumab or in patients with a history of arthropathy.

Importantly, the data from the two long-term studies of efalizumab indicate that the incidence of arthropathy AEs remains stable and low for up to 3 years of continuous treatment. These results, coupled with efficacy data showing that the clinical improvements of the skin after 3 months of efalizumab therapy are maintained throughout 36 months of continuous dosing [5], support the suitability of efalizumab for the chronic, continuous treatment of patients with psoriasis. Reasons for patients' discontinuations in the 36 -month study by Gottlieb et al. [6, 7] were diverse and representative of the overall population included in this analysis and have been described previously. When considering the long-term analysis of the 36-month study (Fig. 2a), it should be noted that the number of patients who remained in the study decreased over time. This discontinuation rate is not unexpected for a study that is 3 years in duration but, by month 36 , there is a small number of patients on which to base comparisons with the first treatment phase. Another factor that may confound betweenphase analysis comparisons was the possible use of concomitant medications for psoriasis after the first treatment phase in the study by Gottlieb et al. [6], which permitted the use of topical corticosteroids and ultraviolet B phototherapy. Accordingly, it should be noted that comparisons of the results between any of the treatment phases of this analysis are observational (i.e., not direct) but do confirm the results of the long-term treatment phase and the placebo-controlled 12-week first treatment phase studies, suggesting that the risk of joint disease is not increased with continued efalizumab treatment and that the incidence of arthropathy is low and similar to placebo. Further investigation is needed to confirm the results of this preliminary analysis of arthropathy events during longterm treatment with efalizumab.

In patients who re-started treatment for a further 12 weeks following an intervention-free period, the proportion of patients who had an arthropathy AE was lower than during the first treatment phase; the same was true for the incidence of arthropathy AEs per patient-year in re-treated patients. Although this scenario is likely to occur infrequently in clinical practice, these data show that if a patient needs to stop (e.g., during pregnancy) and then restart treatment, there appears to be no increased risk of arthropathy AEs.

Although arthritis in patients with psoriasis has a significant impact on QoL [9, 27], it can, in most cases, be managed effectively [8]. In the small minority of patients who develop arthropathy during treatment, the symptoms can be managed successfully with nonsteroidal anti-inflammatory drugs [8].

In conclusion, the results of this pooled analysis show that efalizumab does not appear to increase the risk of developing arthropathy AEs compared with placebo. Long-term studies of efalizumab indicate that the incidence of arthropathy AEs remains stable and low for up to 3 years of continuous treatment.

Acknowledgments This study was sponsored by Serono International S.A. The authors thank Tom Potter, MSc, for his assistance with manuscript preparation.

\section{References}

1. Dustin ML, Springer TA (1988) Lymphocyte function-associated antigen-1 (LFA-1) interaction with intercellular adhesion molecule-1 (ICAM-1) is one of at least three mechanisms for lymphocyte adhesion to cultured endothelial cells. J Cell Biol 107:321-331

2. EMEA (2000) EMEA public statement on infliximab (Remicade) - reports of tuberculosis infections. Accessed 17 January $2006 \mathrm{http}: / /$ www.emea.eu.int/pdfs/human/press/pus/ 444500en.pdf

3. FDA (1995) COSTART: coding symbols for thesaurus of adverse reaction terms, 5th edn. pp 1-540

4. Gordon KB, Papp KA, Hamilton TK, Walicke PA, Dummer W, Li N, Bresnahan BW, Menter A (2003) Efalizumab for patients with moderate to severe plaque psoriasis: a randomized controlled trial. JAMA 290:3073-3080

5. Gottlieb AB, Gordon KB, Hamilton TK, Caro I, Kwon P, Compton P (2005) Maintenance of efficacy and safety with continuous efalizumab therapy in patients with moderate to severe chronic plaque psoriasis: final phase IIIb study results. 
Poster presented at the 63rd Annual Meeting of the American Academy of Dematology (AAD)

6. Gottlieb AB, Gordon KB, Lebwohl MG, Caro I, Walicke PA, Li N, Leonardi CL (2004) Extended efalizumab therapy sustains efficacy without increasing toxicity in patients with moderate to severe chronic plaque psoriasis. J Drugs Dermatol 3:614-624

7. Gottlieb AB, Hamilton T, Caro I, Kwon P, Compton PG, Leonardi CL (2006) Long-term continuous efalizumab therapy in patients with moderate to severe chronic plaque psoriasis: updated results from an ongoing trial. J Am Acad Dermatol 54:S154-S163

8. Hamilton TK (2005) Clinical considerations of efalizumab therapy in patients with psoriasis. Semin Cutan Med Surg 24:19-27

9. Husted JA, Gladman DD, Farewell VT, Cook RJ (2001) Health-related quality of life of patients with psoriatic arthritis: a comparison with patients with rheumatoid arthritis. Arthritis Rheum 45:151-158

10. Krueger J, Gottlieb A, Miller B, Dedrick R, Garovoy M, Walicke P (2000) Anti-CD11a treatment for psoriasis concurrently increases circulating $\mathrm{T}$-cells and decreases plaque $\mathrm{T}$ cells, consistent with inhibition of cutaneous T-cell trafficking. J Invest Dermatol 115:333

11. Kuypers TW, Roos D (1989) Leukocyte membrane adhesion proteins LFA-1, CR3 and p150,95: a review of functional and regulatory aspects. Res Immunol 140:461-486

12. Lebwohl M et al (2003) A novel targeted T-cell modulator, efalizumab, for plaque psoriasis. N Engl J Med 349:2004-2013

13. Leonardi CL, Papp KA, Gordon KB, Menter A, Feldman SR, Caro I, Walicke PA, Compton PG, Gottlieb AB (2005) Extended efalizumab therapy improves chronic plaque psoriasis: results from a randomized phase III trial. J Am Acad Dermatol 52:425-433

14. Menter A, Gordon K, Carey W, Hamilton T, Glazer S, Caro I, Li N, Gulliver W (2005) Efficacy and safety observed during 24 weeks of efalizumab therapy in patients with moderate to severe plaque psoriasis. Arch Dermatol 141:31-38

15. Menter A, Hamilton TK, Caro I, Kwon P, Compton P, Papp KA (2005) Safety and tolerability of efalizumab therapy for patients with moderate to severe chronic plaque psoriasis: results of an open-label phase IIIb multicenter trial. Poster presented at the 63rd Annual Meeting of the American Academy of Dematology (AAD)

16. Papp K, Miller B, Gordon KB, Caro I, Kwon P, Comptom PG, Leonardi CL (2006) Efalizumab retreatment in patients with moderate to severe chronic plaque psoriasis. J Am Acad Dermatol Suppl (in press)

17. Papp KA, Bressnick R, Fretzin S, Goffe B, Kempers S, Gordon KB (2005) The safety of efalizumab in adults with chronic moderate to severe plaque psoriasis: a Phase IIIb randomized, controlled trial. Int J Dermatol (in press)

18. Reich K, Nestle FO, Papp K, Ortonne JP, Evans R, Guzzo C, Li S, Dooley LT, Griffiths CE (2005) Infliximab induction and maintenance therapy for moderate-to-severe psoriasis: a phase III, multicentre, double-blind trial. Lancet 366:13671374

19. Scheinfeld N (2004) Off-label uses and side effects of infliximab. J Drugs Dermatol 3:273-284

20. Scheinfeld N (2005) Alefacept: a safety profile. Expert Opin Drug Saf 4:975-985

21. Springer TA, Dustin ML, Kishimoto TK, Marlin SD (1987) The lymphocyte function-associated LFA-1, CD2, and LFA3 molecules: cell adhesion receptors of the immune system. Annu Rev Immunol 5:223-252

22. Sterry W, Dubertret L, Papp K, Chimenti S, Larsen CG (2004) Efalizumab for patients with moderate to severe chronic plaque psoriasis: results of the international, randomised, controlled phase III clinical experience acquired with Raptiva (CLEAR) trial. poster presented at the 34th Annual European Society for Dermatological Research (ESDR) Meeting, ABST no. 386

23. Tristani-Firouzi P, Krueger GG (1998) Efficacy and safety of treatment modalities for psoriasis. Cutis 61:11-21

24. Vigliani G (2002) Biogen safety presentation on Alefacept to the FDA. Accessed 17 January 2006 http://www.fda.gov/ ohrms/dockets/ac/02/slides/3865S1_04_Biogen-Safety/ sld007.htm

25. Werther WA et al (1996) Humanization of an anti-lymphocyte function-associated antigen (LFA)- 1 monoclonal antibody and reengineering of the humanized antibody for binding to rhesus LFA-1. J Immunol 157:4986-4995

26. Yamauchi PS, Gindi V, Lowe NJ (2004) The treatment of psoriasis and psoriatic arthritis with etanercept: practical considerations on monotherapy, combination therapy, and safety. Dermatol Clin 22:449-459, ix

27. Zachariae H, Zachariae R, Blomqvist K, Davidsson S, Molin L, Mork C, Sigurgeirsson B (2002) Quality of life and prevalence of arthritis reported by 5,795 members of the Nordic psoriasis associations. Data from the Nordic Quality of Life Study. Acta Derm Venereol 82:108-113 